\title{
SODIUM AND CHLORIDE OF THE AQUEOUS HUMOUR OF NORMAL AND SCORBUTIC GUINEA-PIGS
}

BY

\author{
J. W. RIDGE
}

Ophthalmological Research Unit (Medical Research Council), Institute of Ophthalmology, University of London

THE study made by Scholz $(1950,1953)$ of the distribution of sodium between $\frac{\overrightarrow{\vec{\omega}}}{\stackrel{\sigma}{\sigma}}$ the aqueous humour and the plasma of the guinea-pig brought to light two $\frac{0}{0}$. interesting results. First, it showed that the aqueous-plasma distribution of $\dot{\omega}$ sodium in the guinea-pig was markedly different from that found in other 0 species which had been investigated. The value of the steady-state ratio of $\underset{\omega}{\mathcal{E}}$ sodium in the guinea-pig aqueous to that in the plasma was found to be $\circ$ $1.024 \pm 0.0055$ (23) (Scholz, 1950), compared with 0.936 in the horse; $0.945 \stackrel{\text {. }}{-}$ in the steer; 0.943 sheep; $0.935 \mathrm{pig} ; 0.940$ goat; 0.943 rabbit; $0.965 \mathrm{dog} ; \underset{\mathbb{D}}{\mathscr{W}}$ and 0.960 cat (Davson, 1953). Secondly, Scholz (1953) showed that in the $\frac{\mathbb{O}}{\mathbb{D}}$ scorbutic guinea-pig the steady-state ratio fell to $0 \cdot 948 \pm 0.01$ (21), a value $\overline{3}$ very close to that for plasma and its dialysate; this suggested to Scholz $\stackrel{\mathbb{\Phi}}{\sim}$ " that ascorbic acid is essential for the secretion of sodium into the aqueoug $\overrightarrow{0}$ from the plasma". This result was therefore considered to lend support to the hypothesis of Friedenwald and others (1943) regarding the part played by ascorbic acid in the formation of the aqueous humour. Since this finding has such a direct bearing on one of the central problems of aqueous humour dynamics, namely the factors responsible for the formation of the $\frac{\bar{D}}{\mathrm{Q}}$ aqueous, it was decided to submit it to further test.

Let us assume that scurvy is without effect on the plasma sodium concentration (an assumption which is justified below), and that throughout Scholz's experiments it remained constant at about $140 \mathrm{mEq} . / \mathrm{kg} . \mathrm{H}_{2} \mathrm{O}$, then the ratio of 1.024 for the normal animal indicates that the aqueous sodium concentration was $143.36 \mathrm{mEq} . / \mathrm{kg} . \mathrm{H}_{2} \mathrm{O}$. In the scorbutic animal, with a $\frac{0}{7}$ ratio of 0.948 , the aqueous sodium concentration must have been about $132.72 \mathrm{mEq}$. $/ \mathrm{kg}$. $\mathrm{H}_{2} \mathrm{O}$. These figures show that scurvy is accompanied by a decrease in the aqueous sodium concentration of about $10.64 \mathrm{mEq} . / \mathrm{kg}$. $\mathrm{H}_{2} \mathrm{O}$, and further that to maintain electrical neutrality there must have been either an entrance of an equivalent amount of other cations, or an equivalent decrease of anion, or compensatory changes in both.

It is extremely unlikely on $a$ priori grounds that such a large loss of sodium could be made good by other cations without profound alterations in the character of the blood-aqueous barrier and there are no indications at the moment that such alterations have occurred. It seems much more reasonable to suppose that any necessary adjustment would manifest itself in the 
anion concentration, and here the most likely candidate is the chloride ion. The part played in such an adjustment by the absence of ascorbate ion in scurvy is demonstrably small. In the normal guinea-pig the aqueous ascorbate concentration is of the order of $0.6 \mathrm{mEq} . / \mathrm{kg}$. $\mathrm{H}_{2} \mathrm{O}$ (Linnér, 1952), and it can therefore account for only a small part of the discrepancy. For these reasons it was decided to extend Scholz's experiments to the chloride ion; and to investigate the concentration of this ion in the aqueous and plasma of normal and scorbutic guinea-pigs and also in a group of guineapigs whose plasma ascorbate level had been maintained above saturation level for several hours. It was also decided to attempt to confirm Scholz's sodium results by an entirely different technique.

\section{Methods}

Adult guinea-pigs of about $600 \mathrm{~g}$. were randomly selected from stock. Those in the normal group were fed on rabbit pellets supplemented with hay and cabbage and had free access to water at all times. The scorbutic group were fed a diet of roasted crushed oats and bran and water ad lib. Scurvy developed quickly on this diet and after 10-12 days no ascorbate could be detected in the aqueous humour. If the animals were left longer than this the clinical signs of scurvy soon appeared, e.g. a marked loss of weight and haemorrhagic lesions in the buccal membranes. Animals with these symptoms were in very poor condition and for the most part failed to respond to injections of ascorbic acid. It is probable that there was a widespread impairment of essential functions and it is not easy to separate the effects of such damage from ascorbic acid deficiency pure and simple. For this reason animals in this category were rejected.

The plasma ascorbate saturation level was exceeded for a period of 6 hours (i.e. long enough to achieve steady-state conditions in the eye) by a series of intraperitoneal injections of a 3 per cent. (w/v) solution of ascorbic acid. An initial injection of $0.4 \mathrm{ml}$. $(12 \mathrm{mg}$. ascorbic acid) was given followed by $0.1 \mathrm{ml} .(3 \mathrm{mg}$.) at half-hourly intervals. Blood was taken by cardiac puncture from the conscious animal. Heparin was used as an anticoagulant and was freed from sodium or chloride ions by being passed down the appropriate ion exchange column. The cells were immediately spun down and any haemolysed samples were rejected. The animals were killed by a blow on the neck and the aqueous samples, about $30 \mu \mathrm{l}$, taken immediately in calibrated micropipettes.

The total solids of the plasma were determined by drying $\left(110^{\circ} \mathrm{C}\right.$. overnight) weighed samples of plasma and the results were used in the calculation of the results.

Sodium was determined by flame photometry and chloride by the method of Sendroy (1937).

To establish the equilibrium ratio between guinea-pig plasma and its dialysate, several samples of plasma were dialysed for about 20 hours against initially isotonic saline across a collodion membrane. Total solids in the plasma after dialysis were determined as described above and used in the calculations. The dialysate was tested for the presence of protein and the sample rejected if this were found to be present.

\section{Results}

The anticipated compensatory change in the chloride concentration was not found. In the normal guinea-pig the chloride concentration of the aqueous humour was $107 \cdot 32 \pm 1.38 \mathrm{mEq} . / \mathrm{kg} . \mathrm{H}_{2} \mathrm{O}(12)$, and that of the plasma $121 \cdot 32 \pm 1.36 \mathrm{mEq} . / \mathrm{kg} . \mathrm{H}_{2} \mathrm{O}(12)$. The mean steady-state ratio (aqueous to plasma) was $0 \cdot 89 \pm 0 \cdot 01$ (12). 
In the scorbutic animal the values were essentially the same: aqueous humour chloride concentration $108 \cdot 00 \pm 1 \cdot 79 \mathrm{mEq} . / \mathrm{kg} . \mathrm{H}_{2} \mathrm{O}(14)$; plasma chloride concentration $117 \cdot 47 \pm 1.63 \mathrm{mEq} . / \mathrm{kg} . \mathrm{H}_{2} \mathrm{O}$ (13); corresponding steady-state ratio $0.91 \pm 0.01$ (13).

It was also found that saturation with ascorbic acid had no effect on either the aqueous humour or plasma chloride concentrations. The experimental findings were: aqueous, $110 \cdot 11 \pm 1 \cdot 23 \mathrm{mEq} . \mathrm{Cl} / \mathrm{kg} . \mathrm{H}_{2} \mathrm{O}$ (12); plasma $120.03 \pm 0.99 \mathrm{mEq}$. $\mathrm{Cl} / \mathrm{kg}$. $\mathrm{H}_{2} \mathrm{O}(12)$, and the mean steady-state ratio $0.90 \pm 0.01$ (12). These results are summarized in Table $\mathrm{I}$.

TABLE I

DISTRIBUTION OF CHLORIDE BETWEEN AQUEOUS HUMOUR AND PLASMA OF NORMAL, SCORBUTIC, AND ASCORBIC ACID SATURATED GUINEA-PIGS

\begin{tabular}{lll|c|c|c}
\hline \multicolumn{1}{c}{ Group } & & \multicolumn{3}{c}{ mEq. Cl. kg. $\mathrm{H}_{2} \mathrm{O}$} \\
\cline { 3 - 6 } & & & Aqueous Humour & Plasma & Aqueous Humour/Plasma \\
\hline Normal & $\ldots$ & $\ldots$ & $107 \cdot 32$ & $121 \cdot 32$ & 0.89 \\
\hline Scorbutic & $\ldots$ & $\ldots$ & 108.00 & 117.47 & 0.91 \\
\hline Saturated & $\ldots$ & $\ldots$ & $110 \cdot 11$ & 120.03 & 0.90
\end{tabular}

The value of steady-state ratio (aqueous to plasma) for sodium $1.04 \pm 0.01$ (24) agreed with that found by Scholz (1.024), and the absolute values were $143.91 \pm 0.72 \mathrm{mEq} . / \mathrm{kg}$. $\mathrm{H}_{2} \mathrm{O}$ (24) for the aqueous, and $138.62 \pm 0.98$ $\mathrm{mEq} . / \mathrm{kg} . \mathrm{H}_{2} \mathrm{O}$ (24) for the plasma.

On the results for the scorbutic animal Scholz and the present author part company, for in the present experiments no difference in the aqueous-plasma sodium distribution could be detected as between normal and scorbutic animals. In the aqueous of the scorbutic animal there was $144 \cdot 73 \pm 0.71$ $\mathrm{mEq}$. $\mathrm{Na} / \mathrm{kg} . \mathrm{H}_{2} \mathrm{O}(26)$ and in the plasma $139 \cdot 77 \pm 1.00 \mathrm{mEq} . \mathrm{Na} / \mathrm{kg} \cdot \mathrm{H}_{2} \mathrm{O}$ (26). The corresponding steady-state ratio was $1.04 \pm 0.01$ (26). Nor did saturation with ascorbic acid have any marked effect on the ratio although the absolute values from which it was calculated were slightly higher. The steady-state ratio in this case was $1.03 \pm 0.01$ (18) and the absolute values were $148.66 \pm 0.84 \mathrm{mEq} . \mathrm{Na} / \mathrm{kg} . \mathrm{H}_{2} \mathrm{O}(18)$ in the aqueous and $144.68 \pm 0.69$ $\mathrm{mEq}$. $\mathrm{Na} / \mathrm{kg} \cdot \mathrm{H}_{2} \mathrm{O}(18)$ in the plasma. The physiological significance-if any-of the raised plasma and aqueous sodium concentrations in the saturated animals is unknown; the important point in the present context is that the distribution is unchanged. The present sodium results and those reported by Scholz are gathered together for ease of reference in Table II (opposite).

The total solids in guinea-pig plasma varied between 5.64 per cent. and 6.42 per cent. with a mean at $6 \cdot 03$. This value agrees well with that found by Bárány (1951) and Scholz (1953). No systematic difference between the groups could be detected. 
TABLE II

DISTRIBUTION OF SODIUM BETWEEN AQUEOUS HUMOUR AND PLASMA OF NORMAL, SCORBUTIC, AND ASCORBIC ACID SATURATED GUINEA-PIGS

\begin{tabular}{|c|c|c|c|c|}
\hline \multirow{2}{*}{ Group } & \multicolumn{4}{|c|}{$\mathrm{mEq} . \mathrm{Na} / \mathrm{kg} . \mathrm{H}_{2} \mathrm{O}$} \\
\hline & $\begin{array}{l}\text { Aqueous } \\
\text { Humour }\end{array}$ & Plasma & $\begin{array}{l}\text { Aqueous } \\
\text { Humour } \\
\text { Plasma }\end{array}$ & $\begin{array}{c}\text { Aqueous Humour } \\
\text { Plasma } \\
\text { (Scholz 1950, 1953) }\end{array}$ \\
\hline Normal & $143 \cdot 91$ & $138 \cdot 62$ & $1 \cdot 04$ & $1 \cdot 024$ \\
\hline Non-scorbutic Control & - & - & - & 1.015 \\
\hline Scorbutic & $144 \cdot 73$ & $139 \cdot 77$ & $1 \cdot 04$ & 0.948 \\
\hline Saturated & $148 \cdot 66$ & $144 \cdot 68$ & $1 \cdot 03$ & - \\
\hline
\end{tabular}

The results of the experiments in which plasma was allowed to come into equilibrium with protein-free saline showed the ratio of the sodium concentration in the dialysate to that in the plasma to be $0.94 \pm 0.006$ (15), and that of the chloride ion to be $1.00 \pm 0.004$ (21).

\section{Discussion}

The obvious point of departure for this discussion is to search for the cause of the discrepancy between the present findings and those of Scholz. Entirely different methods for the determination of sodium were used in the two cases. Scholz used radioactive $\mathrm{Na}^{22}$ administered intraperitoneally as a solution of one of its salts 24 hours before the aqueous and plasma samples were taken. The measurement of the radioactivity of the samples seems to be beyond reproach and the result for the normal guinea-pig has been confirmed by Kinsey (Scholz, 1950) “ using ordinary analytical techniques”. This particular result was also confirmed by the present author using flame photometry which was shown to give a quantitative recovery of sodium added to both plasma and aqueous. The only point of difference seems to lie in the severity of the scurvy that was allowed to develop in the experimental animals. Scholz kept his animals on a scurvy-producing diet for " about 3 weeks" and did not use them until " a severe degree of clinical scurvy was manifest". It is arguable whether the animals should have been allowed to deteriorate to such an extent, for it is well known that in severe scurvy there occur irreversible changes which are probably secondary to the vitamin deficiency. The present author has attempted to avoid this extra variable by allowing only a subclinical state of scurvy to develop. Furthermore, if one accepts, as a working hypothesis, the role attributed by Friedenwald and others (1943) to ascorbic acid in the formation of the aqueous there seems to be no need to allow the scurvy to develop beyond the subclinical stage. The absence of ascorbate from the plasma without its subsequent complications should be sufficient and this was the condition aimed at in these 
experiments. It is a comparatively simple matter to decide whether such a state has been attained, for, owing to the avidity with which the ciliary processes take up ascorbate from the plasma especially at low plasma ascorbate concentrations, the aqueous humour ascorbate is a sensitive indicator of the presence of the vitamin in the plasma. If no ascorbate is detectable in the aqueous, one may assume with a high degree of confidence that the plasma is also ascorbate free. This was the case in the present experiments, and I am of the opinion that these experimental conditions are capable of providing a more significant answer to the question whether or not ascorbic acid is involved in the movement of sodium across the blood aqueous barrier.

When guinea-pig plasma was at equilibrium with its dialysate the ratio of the concentration of sodium in the dialysate to that in the plasma was 0.94 . In vivo, the steady-state ratio of sodium is 1.04 , i.e. there is a 10 per cent. excess of sodium in the aqueous compared with the plasma dialysate, and it is inferred that the maintenance of this excess requires the continuous expenditure of energy, presumably in the ciliary processes. Friedenwald and Stiehler (1938) have shown that a possible source of this energy lies in the difference of potential which they found to exist between the epithelium and stroma of the ciliary body. They also concluded that ascorbic acid played the part of a mediator in the enzyme complex responsible for the maintenance of this potential. On the other hand, Bárány (1951) has shown that the rate of flow of aqueous is independent of the nutritional state of the animal with respect to ascorbic acid. If, as seems probable, the transfer of sodium across the blood-aqueous barrier is related to the formation and rate of flow of aqueous as a whole, then the present results, namely that neither the sodium of the aqueous humour (as a direct consequence) nor the chloride (as an indirect consequence) is affected by ascorbate depletion or saturation, seem to support Bárány's findings rather than those of Friedenwald.

The results of this work seem to suggest two possibilities:

(i) That ascorbic acid may be involved in the maintenance of the potential difference between the ciliary epithelium and stroma, but that the transfer of sodium across the blood-aqueous barrier is not dependent on this mechanism.

(ii) That the transfer of sodium is related to the potential difference, but that ascorbic acid plays no part in its maintenance.

\section{Summary}

(1) The steady-state ratio of the concentration of sodium and of chloride in the aqueous humour to that in the plasma have been investigated in normal, scorbutic, and ascorbic acid saturated guinea-pigs.

(2) The sodium ratio (aqueous to plasma), confirming earlier work, has been shown to be 1.04 , a value considerably in excess of that for several 
other animal species. The value is unaffected by ascorbic acid depletion or saturation, and in this respect the present results are at variance with those of Scholz (1953).

(3) The chloride ratio (aqueous to plasma) has been shown to be about 0.90 , and also unaffected by scurvy or saturation with ascorbic acid. This result is in harmony with the sodium findings.

I wish to express my thanks to Sir Stewart Duke-Elder for his interest in this work and to Miss Barbara Burton for technical assistance. The cost of this work was borne by the Medical Research Council.

\section{REFERENCES}

BÁRÁNY, E. (1951). Arch. Ophthal. (Chicago), 46, 326.

Davson, H. (1953). Brit. med. Bull., 9, 5.

FriedenWald, J. S., BuschKe, W., and Michel, H. O. (1943). Arch. Ophthal. (Chicago), 29, 535. and STIEHLER, R. D. (1938). Ibid., 20, 761.

LINNÉR, E. (1952). Acta physiol. scand., 26, 57.

SCHOLZ, R. O. (1950). Amer. J. Ophthal., 33, 420. (1953). Ibid., 36, No. 6, Pt. 2, p. 64.

Sendroy, J. (1937). J. biol. Chem., 120, 335. 